\title{
Update on biomarkers for the detection of lung cancer
}

\author{
This article was published in the following Dove Press journal: \\ Lung Cancer:Targets and Therapy \\ II June 2012 \\ Number of times this article has been viewed
}

\author{
Eloisa Jantus-Lewintre' \\ Marta Usó! \\ Elena Sanmartín' \\ Carlos Camps ${ }^{1-3}$ \\ 'Molecular Oncology Laboratory, \\ Fundación para la Investigación del \\ Hospital General Universitario, \\ Valencia, Spain; ${ }^{2}$ Deparment of \\ Medical Oncology, Consorcio Hospital \\ General Universitario, Valencia, Spain; \\ ${ }^{3}$ Department of Medicine, Universitat \\ de València, Valencia, Spain
}

Correspondence: Carlos Camps

Servicio de Oncología Médica, Hospital General Universitario de Valencia, Av.

Tres Cruces s/n, 46014 Valencia, Spain

$\mathrm{Tel}+3496 \mid 972$ I5 I

Fax +3496I 972 I23

Email camps_car@gva.es

\begin{abstract}
Patients at risk for lung cancer may have subclinical disease for years before presentation. The diagnosis of this disease is primarily based on symptoms, and detection often occurs after curative intervention is no longer possible. At present, no lung cancer early-detection biomarker is clinically available. This study reviews the most recent advances in early detection and molecular diagnostic biomarkers for the detection of lung cancer. This review includes an overview of the various biological specimens and matrices in which these biomarkers could be analyzed, as well as the diverse strategies and approaches for identifying new biomarkers that are currently being explored. Several novel and attractive biomarker candidates for the early detection of lung cancer exist. A remarkable shift is taking place from research based on single markers to analyzing signatures that are more complex in order to take advantage of new highthroughput technologies. However, it is still necessary to validate the most promising markers and the standardization of procedures that will lead to specific clinical applications.
\end{abstract}

Keywords: biomarker, detection, lung cancer, diagnosis

\section{Introduction}

Lung cancer is a global public health concern. The average five-year lung cancer survival rate in Europe is approximately $15 \% .{ }^{1}$ More people die from lung cancer than from breast, colon, and prostate cancer combined. ${ }^{2}$ Nevertheless, the five-year survival rate in early-stage, operable, non-small cell lung cancer (NSCLC) is approximately $50 \%-70 \%$. The five-year survival rate drops to $2 \%-5 \%$ for patients whose cancers are diagnosed after their tumors have spread distantly. ${ }^{3}$ At present, the diagnosis of lung cancer is primarily based on symptoms (eg, cough, chest pain, hemoptysis, shortness of breath), and detection often occurs when curative intervention (ie, surgery) is no longer possible.

Although early detection can save lives, screening tests for high-risk individuals using sputum cytology or chest X-rays have not resulted in improvements in diseasespecific survival. ${ }^{4,5}$ Patients at risk for lung cancer may have subclinical disease for years before presentation, and until now, no validated model that includes molecular biomarkers of cancer risk have been developed. The clinical challenge, therefore, is to develop a non-invasive approach based on molecular biomarkers that may significantly improve the assessment of risk, early diagnosis, and application of chemoprevention for lung cancer.

This review presents and discusses the most recent advances in early detection and molecular diagnostic biomarkers for the detection of lung cancer, including an overview of the different matrices with which these biomarkers could be analyzed. 


\section{Early detection of lunch cancer: the role of $C T$ screening}

Low-dose chest computed tomography (CT) scans are proven to be effective tools for the detection of early-stage resectable diseases. Several Phase 2 non-randomized trials of CT screening of high-risk individuals (current or former smokers) have shown that $\mathrm{CT}$ screening detects small size lung cancers of $12-15 \mathrm{~mm}$ in diameter. When these results are compared with those of a validated control group, CT scans detected three times more lung cancer than would be expected. ${ }^{6-8}$

The results from the National Lung Screening Trial (NLST, the largest randomized trial) were published recently. This study enrolled 53,454 persons at high risk for lung cancer in order to determine the real impact of screening with low-dose CT screening on lung cancer mortality at the population level. The participants were randomly assigned to undergo three annual screenings with either low-dose CT or single-view chest X-ray. The results of the NLST show a $20.0 \%$ decrease in mortality from lung cancer in the low-dose CT compared with the chest X-ray. Additionally, a 6.7\% overall mortality reduction was observed in the CT group. ${ }^{9}$ Conversely, low-dose CT screening was associated with a high rate of false positive results. Two other harmful effects of CT screening that should be considered are over-diagnosis and the association of low-dose CT with the development of radiation induced cancers (effects that could not be measured directly and must be assessed in future analyses). Given these results, the potential use of $\mathrm{CT}$ as a lung-cancer screening tool is still a matter of debate.

Due to the contentious results of the image-based screening programs, there is increasing interest in the development of risk prediction models that incorporate genetic and molecular biomarkers for the precise and accurate estimation of risks and are focused on the use of noninvasive or minimally invasive samples, such as blood, sputum, or exhaled breath.

\section{Molecular biomarkers}

A biomarker is defined as a characteristic that is objectively measured and evaluated as an indicator of normal biologic processes, pathogenic processes, or pharmacologic/ pharmacodynamic responses to a therapeutic intervention. ${ }^{10}$ An individual marker may serve more than one purpose and, therefore, can fall into more than one category. In addition, a single biomarker may have different categorizations across tumor types and/or stages of the disease. ${ }^{11}$ The ideal cancer biomarker must be useful for all purposes (diagnosis, prognosis, or the prediction of pharmacological response) and should also be easy to obtain, inexpensive, easy to perform, accurate, and highly informative.

New technologies, including pharmacogenomics, proteomics, metabolomics, and molecular imaging have been introduced in clinical settings and may potentially offer early diagnosis, accurate characterization of the histological subtype of NSCLC, and insight into disease prognosis and response to therapy. However, these techniques are in early development and considerable efforts to standardize them are necessary. Recently, Hanansh et al reviewed the emerging lung cancer serum biomarkers including proteins, DNA methylation patterns, autoantibodies, microRNAs, circulating tumor cells (CTCs), cell-free DNA, and several metabolites. ${ }^{12}$ Table 1 summarizes some relevant studies in the field of biomarkers for lung cancer detection and shows the wide range of specimens, type of biomarkers and detection methods that have been used. An overview of the most recent publications in the area of early diagnosis biomarkers shows that the focus in cancer biomarkers has shifted from searching for single biomarkers to analyzing combined biomarkers, which seems to be more effective in decreasing false positives and increasing detection rates. However, at this time, there are no single or combined validated molecular biomarkers for the early detection of lung cancer despite the considerable number of investigations that have been carried out with this purpose (Table 1).

\section{Selection of the analytical matrix: the biological specimen}

An important pre-analytic issue is choosing the "correct" analytical matrix in which to find new biomarkers. A good biomarker must be detectable in clinically accessible material; therefore, there is an increasing interest in the development of molecular-based minimally- or non-invasive screening methods. Fluid biomarkers include a variety of components found in blood, urine, or other fluids that may reflect the presence of a tumor in the body. ${ }^{13}$

The aim of early lung cancer diagnosis is to detect molecular biomarkers in non-invasive biological specimens before symptoms arise.

\section{Tissue bronchoscopy}

Bronchoscopy, particularly with the help of techniques such as auto-fluorescence bronchoscopy (AFB) and narrow-band imaging, is a suitable technique for detecting preinvasive lesions and early-stage lung cancer in the central airways that cannot be detected by CT technology. ${ }^{14}$ In addition, 
several studies have demonstrated that the use of fluorescence in situ hybridization (FISH) testing for the detection of chromosomal abnormalities is significantly more sensitive than conventional cytology for detecting lung cancer in bronchoscopically obtained bronchial brushing specimens; however, this result was achieved with an increase in false positive diagnoses. ${ }^{15-18}$

Other studies show similar results that demonstrate how equivocal cytology in lung cancer diagnosis can be overcome with additional methods on the same specimen (ie, slide). Adjuvant FISH or DNA-image cytometry in cytologically equivocal diagnoses improves diagnostic accuracy at comparable rates. ${ }^{19}$ Spira et al have identified an airway geneexpression biomarker that may be useful as a screening tool for the evaluation of smokers with suspected lung cancer. They performed gene-expression profiling on histologically normal upper airway epithelial cells obtained at the time of bronchoscopy, with sufficient quantities of high quality RNA for microarray studies from 152 of 208 samples. Their data suggest that combining cytopathology with the geneexpression biomarker improves the diagnostic sensitivity of the overall bronchoscopy procedure from $53 \%$ to $95 \%{ }^{20}$

AFB biopsies were also useful for analyzing microRNA expression by qPCR, allowing to assess different microRNA patterns during the succesive steps of bronchial carcinogenesis. $^{21}$

\section{Blood samples}

The rich content of diverse molecular and cellular elements in blood, which gives information about the health status of an individual, makes it an ideal compartment in which to develop non-invasive diagnostics for cancer. Hanash et al recently reviewed the role of blood-borne biomarkers in cancer screening; this role could be extended from general population risk assessment to treatment response evaluation and recurrence monitoring. ${ }^{12}$

Blood samples comprise a complex matrix composed of a cellular fraction and serum or plasma. CTCs and macromolecules such as lipids, proteins, RNA, microRNA, and DNA that originate from tumor cells can be found in blood. In addition to CTCs, other circulating cells are currently being explored as sources of biomarkers such as immune, stromal, and endothelial cells. ${ }^{13}$

The first detection of cell-free nucleic acids originating from tumor cells and circulating in the serum or plasma of cancer patients, including lung cancer, was reported in 1997. ${ }^{22}$ Several case-control studies have reported higher levels of circulating DNA in patients' blood than in normal healthy controls, showing that DNA may be an important risk factor for the presence of illness and a prognostic index in the follow-up procedure (reviewed by Bremnes et al). ${ }^{23}$ Interestingly, Sozzi et al were able to discriminate NSCLC patients from age-, sex-, and smoking-matched controls according to the amount of circulating plasma DNA, which was determined through the use of real-time quantitative polymerase chain reaction (PCR) amplification of the human telomerase reverse transcriptase gene (hTERT). ${ }^{24}$ Since then, several studies have assessed varying concentrations of free circulating DNA using diverse data analysis methods or laboratory procedures that have resulted in significant differences between lung cancer patients and controls. ${ }^{24-27}$ In contrast to these studies, Tamkovich et al found no significant differences between the amount of DNA in plasma samples of lung cancer patients and healthy subjects. ${ }^{28}$ In general, the vast majority of studies show that higher levels of circulating DNA can be detected in patients with lung cancer compared with disease-free smokers and control subjects, which suggests that the analysis of this biomarker may represent a new non-invasive approach for the early detection of lung cancer.

In terms of circulating nucleic acids, it is also worth considering the value of the isolation and characterization of circulating tumor DNA because a correlation between the detection of molecular alterations (genetic and epigenetic) in the circulating nucleic acids and lung tumor DNA has been demonstrated. ${ }^{29-31}$

Circulating cell-free RNA and miRNA as well as exosomal miRNA content has also been identified as a source of biomarkers for early detection in lung cancer patients. ${ }^{32-34}$ The usefulness of circulating nucleic acid detection in plasma or serum for the early detection of lung cancer has been extensively assessed, but the results are still inconsistent due to the high rate of false negative results (the absence of circulating nucleic acids does not correlate with the absence of cancer). ${ }^{35}$

Recent microarray studies have identified additional early detection signatures using samples from peripheral blood. Showe et al demonstrated the feasibility of using the PBMC gene expression signature to identify early-stage NSCLC in at-risk populations. ${ }^{36}$

The use of blood samples for tumor protein quantification is another point to be addressed in the development of biomarkers for the early detection of lung cancer. Some proteomics biomarkers of lung cancer, such as carcinoembryonic antigen (CEA), cytokeratin-19 fragment (CYFRA), or neuron-specific enolase (NSE) are clinically available, while others (serum amyloid A -SAA-, haptoglobin- $\alpha 2$, or Apo A-1) ${ }^{37}$ still need 
further validation and are not recommended for clinical diagnosis.

Another interesting approach is the detection and characterization of CTCs, which offers new perspectives for researchers. Several available CTC detection platforms were verified in clinical settings that strongly suggest that CTC detection has enormous potential to assist in malignancy diagnosis, estimating prognosis, and monitoring disease recurrence and responses to anticancer therapy. Tanaka et al evaluated the potential of CTC detection as a diagnostic parameter to distinguish malignant from benign lung disease. They found that the CTC count was significantly higher in lung cancer patients compared with nonmalignant patients, but the test showed a low sensitivity for detecting CTCs. ${ }^{38}$ A novel microfluidic platform was recently developed that allows for the isolation of high quantities of rare CTCs. A pilot study using this technology showed that CTCs were detected in most blood samples taken from patients with a variety of malignant tumors, including lung cancer. ${ }^{39}$ Therefore, comparative studies are still necessary to clarify the appropriate methodology for lung CTC detection, with the aim of improving early diagnosis, monitoring the disease, and genotyping tumors.

\section{Exhaled breath condensate}

Exhaled breath condensate (EBC) is a fluid from the airways that can be collected by means of an easy, completely noninvasive, and repeatable procedure that is well accepted by patients. EBC contains both volatile and non-volatile compounds, including cytokines, proteins, and DNA. ${ }^{40}$ The analysis of exhaled air for volatile organic compounds (VOCs) shows that there is a pattern of VOCs that distinguishes lung cancer patients. ${ }^{41-44}$ Even when most VOCs in the cancer patients are higher at baseline compared to the controls, this difference is still evident after surgery. ${ }^{42}$ Therefore, exhaled VOCs cannot be considered specific biomarkers for lung cancer, as they do not seem to be solely produced by tumor tissue, but rather by an epiphenomenon that accompanies lung cancer development.

Various studies have reported genetic changes in DNA found in EBC from lung cancer patients. Carpagnano et al demonstrated that the microsatellite alterations in DNA from the EBC and tumor tissue in NSCLC patients had an overlapping profile consisting of loss of heterozygosity and microsatellite instability. ${ }^{45}$ In another study by Gessner et al, mutations were present in the $\mathrm{EBC}$ of patients with NSCLC, while no mutations were found in the $\mathrm{EBC}$ of the control subjects. ${ }^{46}$
All these findings support the suggestion that EBC may be an appropriate matrix for the non-invasive identification of early markers of NCSLC. On the other hand, a weakness of the use of EBC is that the collection devices can significantly affect the levels of biomarkers obtained; therefore, the values acquired from different devices may not be directly comparable. ${ }^{47}$

\section{Sputum}

Sputum is another potentially attractive non-invasive source of biomarkers for lung cancer. Although it is unlikely that early-stage lung cancers will exfoliate detectable cancer cells in sputum, it is hypothesized that because of field tumorigenesis process, genetic or epigenetic changes in exfoliated cells may reflect an increased risk of lung cancer. ${ }^{48}$ Consequently, many research groups have examined sputum as a matrix in which biomarkers can be determined. Byers et al studied cytologic atypia in a large cohort of smokers and former smokers with chronic obstructive lung diseases. They reported that sputum cytologic atypia is a marker for increased lung cancer risk and examined whether it might complement radiologic imaging in a combined approach to the early detection of lung cancer. ${ }^{49}$ With the intention of improving the diagnostic accuracy of cytologic examination, additional molecular approaches have been investigated, such as gene-promoter methylation analysis ${ }^{50}$ and FISH for chromosomal aneusomy using a four-target DNA FISH probe including EGFR, MYC, 5p15, and CEP6. ${ }^{51}$

Using sputum as starting material, Xie et al reported aberrant miRNA expression in this type of sample, which could be used as a marker for the early diagnosis of NSCLC, 52 especially in adenocarcinomas. ${ }^{53}$ However, there are currently no definitive data indicating that sputum biomarkers are efficient for routine clinical applications to reliably predict individuals at risk of developing lung cancer or who are in the early stages of the disease.

\section{Strategies for the identification of early-detection lung cancer biomarkers \\ Genomic/genetic approaches}

Since human genome sequencing was completed, DNA has been widely studied for the detection of new biomarkers for many diseases. In lung cancer, genomic instability is frequently observed, which includes allelic loss and instability at loci on $3 p$ (fragile histidine triad), $9 \mathrm{p}$ (p16INK4A), and 17p. ${ }^{54-56}$ By analyzing a wide collection of lung adenocarcinomas through high resolution (250k) SNP arrays, Weir et al 
Table I Summary of relevant studies in the field of biomarkers for lung cancer detection

\begin{tabular}{|c|c|c|c|c|c|}
\hline Reference & Sample type & Biomarker type & $\begin{array}{l}\text { Detection } \\
\text { method }\end{array}$ & Number of cases & $\begin{array}{l}\text { Sensitivityl } \\
\text { specificity (\%) }\end{array}$ \\
\hline \multirow[t]{2}{*}{ Halling et al ${ }^{15}$} & Bronquial brushing & Cytology and & Combined cytology & Patients $=89$ & $75 / 83$ \\
\hline & Bronquial washing & chromosomal abnormailities & and FISH & Controls $=48^{\mathrm{a}}$ & $61 / 95$ \\
\hline \multirow[t]{6}{*}{ Spira et $\mathrm{al}^{20}$} & Bronquial brushing & Gene expression & Microarrays & Primary dataset & \\
\hline & & & & Patients $=60$ & $80 / 84$ \\
\hline & & & & Controls $=69^{a}$ & \\
\hline & & & & Validation dataset & \\
\hline & & & & Patients $=18$ & $83 / 76$ \\
\hline & & & & Controls $=17^{\mathrm{a}}$ & \\
\hline \multirow[t]{2}{*}{ Sozzi et $\mathrm{al}^{24}$} & Blood & DNA & PCR & Patients $=100$ & $90 / 86^{b}$ \\
\hline & & & & Controls $=100$ & \\
\hline \multirow[t]{2}{*}{ Tanaka et al ${ }^{38}$} & Blood & CTC & CTC count & Patients $=125$ & $30.4 / 88.0^{c}$ \\
\hline & & & & Controls $=25^{a}$ & \\
\hline \multirow[t]{6}{*}{ Patz et al ${ }^{79}$} & Serum & Proteins & ELISA & Primary dataset & \\
\hline & & & & Patients $=50$ & $89.3 / 84.7$ \\
\hline & & & & Controls $=50$ & \\
\hline & & & & Validation dataset & \\
\hline & & & & Patients $=49$ & $77.8 / 75.4$ \\
\hline & & & & Controls $=48$ & \\
\hline \multirow[t]{2}{*}{ Miura et al ${ }^{66}$} & Serum & Gene expression & RT-PCR & Patients $=112$ & $89 / 72^{d}$ \\
\hline & & & & Controls $=80$ & $71 / 80^{e}$ \\
\hline \multirow[t]{2}{*}{ Zheng et $\mathrm{a}^{33}$} & Plasma & microRNas & RT-PCR & Patients $=74$ & $81.33 / 86.76$ \\
\hline & & & & Controls $=68$ & \\
\hline Jantus- & Plasma & Proteins & ELISA & Patients $=432$ & $74.5 / 85.7$ \\
\hline Lewintre et $\mathrm{al}^{83}$ & & & & Control = 89 & \\
\hline \multirow[t]{6}{*}{ Showe et al ${ }^{36}$} & PBMC & Gene expression & Arrays & Primary dataset & \\
\hline & & & & Patients $=137$ & $91 / 80$ \\
\hline & & & & Controls $=9 \mathrm{I}^{\mathrm{a}}$ & \\
\hline & & & & Validation dataset & \\
\hline & & & & Patients $=38$ & $76 / 82$ \\
\hline & & & & Controls $=17^{a}$ & \\
\hline \multirow[t]{6}{*}{ Yu et al ${ }^{53}$} & Sputum & microRNas & RT-PCR & Primary dataset & \\
\hline & & & & Patients $=36$ & $80.6 / 91.7$ \\
\hline & & & & Controls $=36$ & \\
\hline & & & & Validation dataset & \\
\hline & & & & Patients $=64$ & $70.3 / 80$ \\
\hline & & & & Controls $=58$ & \\
\hline \multirow[t]{2}{*}{ Xie et $a^{52}$} & Sputum & microRNas & RT-PCR & Patients $=23$ & $69.7 / 100$ \\
\hline & & & & Controls $=17^{a}$ & \\
\hline
\end{tabular}

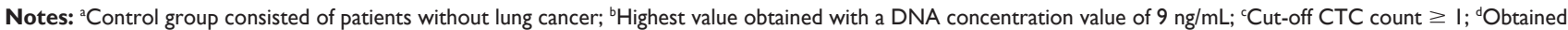
with hTERT; ' ${ }^{\circ}$ btained with EGFR.

Abbreviations: CTC, circulating tumor cell; EGFR, epidermal growth factor receptor; ELISA, enzyme-linked immunosorbent assay; FISH, fluorescence in situ hybridization; hTERT, human telomerase reverse transcriptase gene; PBMC, peripheral blood mononuclear cells; PCR, polymerase chain reaction; RT-PCR, real-time polymerase chain reaction.

identified 57 significantly recurrent events in this type of tumor, but concluded that many of the genes involved in lung adenocarcinoma are yet to be discovered.$^{57}$ Twenty-six of the most prevalent somatic mutations in lung adenocarcinomas have recently been categorized. The most frequently mutated genes include tyrosine kinases, among them the EGFR homologue ERBB4; multiple ephrin receptor genes, notably EPHA3; vascular endothelial growth factor receptor, KDR; and NTRK genes. ${ }^{58}$ The detection of these changes in DNA is considered a potential diagnostic tool, but due to the low frequency of alterations in the specific genes found in biological samples, most of these studies obtained limited sensitivity and specificity.

Over last 5 years, next generation sequencing (NGS) methods have changed genomic analyses, thus providing a more accurate and sensitive detection technology for somatic mutations in tumors. NGS chemistries vary, but the results are similar: millions of sequencing reads of DNA templates are generated in parallel, gathering information of up to $200 \mathrm{~Gb}$, while the read lengths for each DNA template are very short (35-500 bp) compared to the traditional Sanger sequencing method. ${ }^{59}$ This technique can be applied to a 
panel of relevant lung cancer related genes, a comprehensive assortment of signal transducers involved in the signaling of tumor cells, or even to the entire exome or genome of tumor cells. However, the massive amount of information derived from NGS will require impressive data processing tools and very careful interpretation to provide meaningful clinical information. On the other hand, the capacity to generate enormous amounts of information, together with the high specificity of NGS methods, offers a promising new avenue for discovery in many fields of research, especially in identifying molecular biomarkers for early detection and prognosis in lung cancer patients.

\section{Epigenomics/epigenetics}

Epigenetics is defined as the study of the modifications of genes that are not coded in the DNA sequence itself and that are believed to be important in the etiology of diseases such as cancer. Unlike the DNA sequence, epigenetics may be influenced by the environment and may lead to alterations in the expression of genes through various epigenetic factors, such as methylation. In lung cancer cells, hypermethylation of certain regions is associated with promoter silencing of tumor suppressor genes and may serve as an early lung cancer-detection marker (reviewed by Tsou et al). ${ }^{60}$ Elevated levels of methylated genes in plasma have been observed for RASSFIA, p16, APC, FIHT, RARbeta, MGMT, DAPK, tissue inhibitors of metalloproteinase 3 (TIMP-3), and SOCS1 and SOCS3. ${ }^{31,61}$ In sputum, aberrant methylation of p16 and/or MGMT was found in all patients with squamous-cell lung carcinomas who were studied up to 3 years before clinical diagnosis. ${ }^{62}$ Recently, DNA methylation of SHOX2 studied in bronchial lavage samples by differential methylation hybridization (DMH) showed the potential use of this gene in lung cancer detection, even in samples that contained no visible tumor cells. ${ }^{63}$ This result was further confirmed in tumor and adjacent normal tissue samples of patients by analyzing SHOX2 DNA methylation levels. ${ }^{64}$ Therefore, the analysis of methylation profiles in various types of biological specimens (plasma, serum, and sputum) appears to be a promising approach for the early diagnosis of lung cancer.

\section{Transcriptomics: messenger and micro-RNAs}

The isolation of messenger RNA from body fluids such as plasma or serum still presents technical difficulties, which is reflected in the lower number of publications compared to those on DNA. Various approaches for transcriptomics studies in blood samples from lung cancer patients have been performed. For instance, Xi et $\mathrm{al}^{65}$ analyzed messenger RNA for the detection of CTCs in blood with a panel that included CK7, EGFR, SCCA, and SFTB. Miura et al ${ }^{66}$ measured serum hTERT mRNA and epidermal growth factor receptor (EGFR) mRNA levels in lung cancer patients using qPCR assays by observing that hTERT mRNA, especially when combined with EGFR mRNA, has adequate sensitivity and specificity as a biomarker of diagnosis and clinical stage. Gene expression profiles using RNA arrays have also been studied. As mentioned earlier, Showe et al found a gene expression signature in PBMC that distinguished early-stage NSCLC patients from those with non-malignant lung disease. ${ }^{36}$

Research on cancer biomarkers has recently focused on micro-RNAs (miRNAs), a type of non-transcribed short RNA that regulates the translation of mRNA by binding to sequences in the $3^{\prime}$ untranslated region ( $3^{\prime} \mathrm{UTR}$ ). Several studies have demonstrated the critical role that miRNAs play in cancer pathogenesis. ${ }^{67-69}$ Several miRNAs have been detected in tissue, sputum, and peripheral blood in lung cancer patients with remarkable stability, which makes them attractive candidates as diagnostic biomarkers. Mascaux et $\mathrm{al}^{21}$ have recently analyzed the miRNA expression profiling of biopsies obtained by fluorescence bronchoscopy using qPCR. They identified a set of miRNA that were differentially expressed in the successive stages of bronchial carcinogenesis that were also highly predictive of the histological grade. Furthermore, Jiang et $\mathrm{al}^{53}$ describe a panel of seven miRNAs that are expressed differentially in lung adenocarcinomas compared with normal lung tissues. The combination of four of these miRNAs allowed for a distinction between patients with adenocarcinoma and normal subjects. Moreover, these miRNA could be detected in sputum samples by qPCR with high sensitivity and specificity.

The presence of miRNAs in plasma and serum samples has been widely studied. Endogenous plasma miRNAs are highly stable. They are resistant to incubation at $37^{\circ} \mathrm{C}$, freezethaw cycles, and even to RNase activity. ${ }^{70,71}$ The mechanisms by which miRNAs are protected are still unknown, although it has been hypothesized that they may be packaged inside exosomes or associated with other protective molecules. ${ }^{34,72}$ Several studies carried out on plasma and serum have identified patterns of differential expression of miRNAs that allow lung cancer patients to be distinguished from cancerfree control subjects, even in patients with Stage I lung cancer. ${ }^{33,73-75}$ In sum, these results support the hypothesis that 
miRNA expression patterns may serve as biomarkers for the early diagnosis of lung cancer.

\section{Proteomics}

Proteins are the real players in biomarking processes; therefore, they may have a significant advantage over genes in terms of biomarker discovery. Proteomics is becoming a useful tool for biomarker identification in different types of tumors due to the development of high-throughput platforms, which allow for the simultaneous detection of multiple proteins. Two approaches - the identification of individual proteins and protein expression profiling - have been suggested for the application of proteomics in biomarker detection. The role of some plasma proteins as diagnostic biomarkers has been further studied, and some are currently available in the clinical setting (eg, CEA, CYFRA, and NSE). The problem lies in the low specificity and/or sensitivity of these biomarkers, which means they are not recommended for clinical use. ${ }^{76-78}$ Many additional proteins have recently been studied as potential diagnostic biomarkers in lung cancer. Patz et $\mathrm{al}^{79}$ tested a panel of four serum proteins (CEA, retinol-binding protein, $\alpha 1$-antitrypsin, and squamous cell carcinoma antigen) in a matched case-control study including lung cancer patients, in which considerable specificity and sensitivity was obtained. The value of other serum proteins, such as amyloid A, haptoglobin- $\alpha 2$, and a fragment of apolipoprotein A-1, as biomarkers has also been explored, although more clinical validation is needed. ${ }^{80-82}$ Due to the importance of the angiogenic process in cancer, our group recently studied the diagnostic and prognostic implications of vascular endothelial growth factor (VEGF) and its receptor VEGFR-2 in patients with advanced NSCLC, where we observed that both angiogenic markers exhibited higher plasma concentrations in patients compared to the age- and sex-matched controls with adequate specificity and sensitivity. ${ }^{83}$

Comparative protein profiling is another promising method for the detection of protein expression patterns. Advances in new analytical methods such as two-dimensional gel electrophoresis (2DE) and mass spectrometry have made the simultaneous detection of multiple protein changes possible. ${ }^{84,85}$ Tyan et al characterized a list of 1400 proteins in pleural effusion samples from lung adenocarcinoma patients by separating peptides and HPLC-ESI-MS/MS. ${ }^{86}$ Furthermore, Soltermann et al isolated 170 glycoproteins that were also from pleural effusions, including several known lung cancer biomarkers such as CA125, CD44, and $\mathrm{TTF}^{87}$ These studies have some limitations due to their lack of independent validation. Moreover, they are not superior to other lung cancer-diagnosis methods, despite the recent discovery of new biomarkers.

\section{Conclusion}

Cancer biomarker research has recently experienced a remarkable growth in technology, which has resulted in biomarker discoveries from various "omics" including genomics, transcriptomics, proteomics, and metabolomics. Several examples of novel candidate biomarkers for the early detection of lung cancer have emerged following this growth in technology. In conjunction with the use of noninvasively obtained samples, such as blood, sputum, or EBC, this technological growth represents a significant advance in the field of diagnostic biomarkers for lung cancer. The tasks ahead are to select the most promising markers (single or a panel) for the early detection of lung cancer in order to choose the correct specimen and novel methodology and to optimize and standardize procedures for the implementation of successful validation studies that will lead to specific clinical applications.

\section{Disclosure}

The authors report no confilicts of interest in this work.

\section{References}

1. Ferlay J, Parkin DM, Steliarova-Foucher E. Estimates of cancer incidence and mortality in Europe in 2008. Eur J Cancer. 2010;46(4): 765-781.

2. Jemal A, Bray F, Center MM, Ferlay J, Ward E, Forman D. Global cancer statistics. CA Cancer J Clin. 2011;61(2):69-90.

3. Goldstraw P, Crowley J, Chansky K, et al. The IASLC Lung Cancer Staging Project: proposals for the revision of the TNM stage groupings in the forthcoming (seventh) edition of the TNM Classification of malignant tumours. J Thorac Oncol. 2007;2(8):706-714.

4. Melamed MR, Flehinger BJ. Screening for lung cancer. Chest. 1984;86(1):2-3.

5. Marcus PM, Bergstralh EJ, Zweig MH, Harris A, Offord KP, Fontana RS Extended lung cancer incidence follow-up in the Mayo Lung Project and overdiagnosis. J Natl Cancer Inst. 2006;98(11):748-756.

6. Pastorino U, Bellomi M, Landoni C, et al. Early lung-cancer detection with spiral CT and positron emission tomography in heavy smokers: 2-year results. Lancet. 2003;362(9384):593-597.

7. Henschke CI, Yankelevitz DF, Libby DM, Pasmantier MW, Smith JP, Miettinen OS. Survival of patients with stage I lung cancer detected on CT screening. N Engl J Med. 2006;355(17):1763-1771.

8. Henschke CI, McCauley DI, Yankelevitz DF, et al. Early Lung Cancer Action Project: overall design and findings from baseline screening. Lancet. 1999;354(9173):99-105.

9. Aberle DR, Adams AM, Berg CD, et al. Reduced lung-cancer mortality with low-dose computed tomographic screening. $N$ Engl J Med. 2011; 365(5):395-409.

10. Atkinson AJ, Colburn WA, DeGruttola VG, et al. Biomarkers and surrogate endpoints: preferred definitions and conceptual framework Clin Pharmacol Ther. 2001;69(3):89-95.

11. Febbo PG, Ladanyi M, Aldape KD, et al. NCCN Task Force report: Evaluating the clinical utility of tumor markers in oncology. $J$ Natl Compr Canc Netw. 2011;9(Suppl 5):S1-S32. 
12. Hanash SM, Baik CS, Kallioniemi O. Emerging molecular biomarkers blood-based strategies to detect and monitor cancer. Nat Rev Clin Oncol. 2011;8(3):142-150.

13. Martin KJ, Fournier MV, Reddy GP, Pardee AB. A need for basic research on fluid-based early detection biomarkers. Cancer Res. 2010;70(13):5203-5206.

14. McWilliams A, Lam B, Sutedja T. Early proximal lung cancer diagnosis and treatment. Eur Respir J. 2009;33(3):656-665.

15. Halling KC, Rickman OB, Kipp BR, Harwood AR, Doerr CH, Jett JR. A comparison of cytology and fluorescence in situ hybridization for the detection of lung cancer in bronchoscopic specimens. Chest. 2006;130(3):694-701.

16. Voss JS, Kipp BR, Halling KC, et al. Fluorescence in situ hybridization testing algorithm improves lung cancer detection in bronchial brushing specimens. Am J Respir Crit Care Med. 2010;181(5): $478-485$.

17. Bubendorf L, Muller P, Joos L, et al. Multitarget FISH analysis in the diagnosis of lung cancer. Am J Clin Pathol. 2005;123(4):516-523.

18. Massion PP, Zou Y, Uner H, et al. Recurrent genomic gains in preinvasive lesions as a biomarker of risk for lung cancer. PLoS One. 2009;4(6):e5611.

19. Schramm M, Wrobel C, Born I, et al. Equivocal cytology in lung cancer diagnosis: improvement of diagnostic accuracy using adjuvant multicolor FISH, DNA-image cytometry, and quantitative promoter hypermethylation analysis. Cancer Cytopathol. 2011;119(3):177-192.

20. Spira A, Beane JE, Shah V, et al. Airway epithelial gene expression in the diagnostic evaluation of smokers with suspect lung cancer. Nat Med. 2007;13(3):361-366.

21. Mascaux C, Laes JF, Anthoine G, et al. Evolution of microRNA expression during human bronchial squamous carcinogenesis. Eur Respir J. 2009;33(2):352-359.

22. Sidransky D. Nucleic acid-based methods for the detection of cancer. Science. 1997;278(5340):1054-1059.

23. Bremnes RM, Sirera R, Camps C. Circulating tumour-derived DNA and RNA markers in blood: a tool for early detection, diagnostics, and follow-up? Lung Cancer. 2005;49(1):1-12.

24. Sozzi G, Conte D, Leon M,et al. Quantification of free circulating DNA as a diagnostic marker in lung cancer. J Clin Oncol. 2003;21(21): 3902-3908

25. Paci M, Maramotti S, Bellesia E, et al. Circulating plasma DNA as diagnostic biomarker in non-small cell lung cancer. Lung Cancer. 2009;64(1):92-97.

26. Sirera R, Bremnes RM, Cabrera A, et al. Circulating DNA is a useful prognostic factor in patients with advanced non-small cell lung cancer. J Thorac Oncol. 2011;6(2):286-290.

27. Yoon KA, Park S, Lee SH, Kim JH, Lee JS. Comparison of circulating plasma DNA levels between lung cancer patients and healthy controls. J Mol Diagn. 2009;11(3):182-185.

28. Tamkovich SN, Litviakov NV, Bryzgunova OE, et al. Cell-surfacebound circulating DNA as a prognostic factor in lung cancer. Ann NY Acad Sci. 2008;1137:214-217.

29. Andriani F, Conte D, Mastrangelo T, et al. Detecting lung cancer in plasma with the use of multiple genetic markers. Int J Cancer. 2004; 108(1):91-96.

30. Fujiwara K, Fujimoto N, Tabata M, et al. Identification of epigenetic aberrant promoter methylation in serum DNA is useful for early detection of lung cancer. Clin Cancer Res. 2005;11(3):1219-1225.

31. Ostrow KL, Hoque MO, Loyo M, et al. Molecular analysis of plasma DNA for the early detection of lung cancer by quantitative methylationspecific PCR. Clin Cancer Res. 2010;16(13):3463-3472.

32. Mitas M, Hoover L, Silvestri G, et al. Lunx is a superior molecular marker for detection of non-small cell lung cancer in peripheral blood [corrected]. J Mol Diagn. 2003;5(4):237-242.

33. Zheng D, Haddadin S, Wang Y, et al. Plasma microRNAs as novel biomarkers for early detection of lung cancer. Int J Clin Exp Pathol. 2011;4(6):575-586.
34. Rabinowits G, Gercel-Taylor C, Day JM, Taylor DD, Kloecker GH. Exosomal microRNA: a diagnostic marker for lung cancer. Clin Lung Cancer. 2009;10(1):42-46.

35. Fleischhacker M, Schmidt B. Circulating nucleic acids (CNAs) and cancer - a survey. Biochim Biophys Acta. 2007;1775(1):181-232.

36. Showe MK, Vachani A, Kossenkov AV, et al. Gene expression profiles in peripheral blood mononuclear cells can distinguish patients with nonsmall cell lung cancer from patients with nonmalignant lung disease. Cancer Res. 2009;69(24):9202-9210.

37. Sung HJ, Cho JY. Biomarkers for the lung cancer diagnosis and their advances in proteomics. BMB Rep. 2008;41(9):615-625.

38. Tanaka F, Yoneda K, Kondo N, et al. Circulating tumor cell as a diagnostic marker in primary lung cancer. Clin Cancer Res. 2009; 15(22):6980-6986.

39. Nagrath S, Sequist LV, Maheswaran S, et al. Isolation of rare circulating tumour cells in cancer patients by microchip technology. Nature. 2007;450(7173):1235-1239.

40. Chan HP, Lewis C, Thomas PS. Exhaled breath analysis: novel approach for early detection of lung cancer. Lung Cancer. 2009; 63(2):164-168.

41. Phillips M, Cataneo RN, Cummin AR, et al. Detection of lung cancer with volatile markers in the breath. Chest. 2003;123(6):2115-2123.

42. Poli D, Carbognani P, Corradi M, et al. Exhaled volatile organic compounds in patients with non-small cell lung cancer: cross sectional and nested short-term follow-up study. Respir Res. 2005;6:71.

43. Bajtarevic A, Ager C, Pienz M, et al. Noninvasive detection of lung cancer by analysis of exhaled breath. BMC Cancer. 2009;9:348.

44. Ligor M, Ligor T, Bajtarevic A, et al. Determination of volatile organic compounds in exhaled breath of patients with lung cancer using solid phase microextraction and gas chromatography mass spectrometry. Clin Chem Lab Med. 2009;47(5):550-560.

45. Carpagnano GE, Foschino-Barbaro MP, Spanevello A, et al. $3 p$ microsatellite signature in exhaled breath condensate and tumor tissue of patients with lung cancer. Am J Respir Crit Care Med. 2008; 177(3):337-341.

46. Gessner C, Kuhn H, Toepfer K, Hammerschmidt S, Schauer J, Wirtz H. Detection of p53 gene mutations in exhaled breath condensate of nonsmall cell lung cancer patients. Lung Cancer. 2004;43(2):215-222.

47. Liu J, Conrad DH, Chow S, Tran VH, Yates DH, Thomas PS. Collection devices influence the constituents of exhaled breath condensate. Eur Respir J. 2007;30(4):807-808.

48. Belinsky SA. Gene-promoter hypermethylation as a biomarker in lung cancer. Nat Rev Cancer. 2004;4(9):707-717.

49. Byers T, Wolf HJ, Franklin WA, et al. Sputum cytologic atypia predicts incident lung cancer: defining latency and histologic specificity. Cancer Epidemiol Biomarkers Prev. 2008;17(1):158-162.

50. Belinsky SA, Liechty KC, Gentry FD, et al. Promoter hypermethylation of multiple genes in sputum precedes lung cancer incidence in a highrisk cohort. Cancer Res. 2006;66(6):3338-3344.

51. Varella-Garcia M, Schulte AP, Wolf HJ, et al. The detection of chromosomal aneusomy by fluorescence in situ hybridization in sputum predicts lung cancer incidence. Cancer Prev Res. 2010;3(4):447-453.

52. Xie Y, Todd NW, Liu Z, et al. Altered miRNA expression in sputum for diagnosis of non-small cell lung cancer. Lung Cancer. 2010;67(2): $170-176$.

53. Yu L, Todd NW, Xing L, et al. Early detection of lung adenocarcinoma in sputum by a panel of microRNA markers. Int J Cancer. 2010;127(12): 2870-2878.

54. Sozzi G, Veronese ML, Negrini M, et al. The FHIT gene 3p14.2 is abnormal in lung cancer. Cell. 1996;85(1):17-26.

55. Mao L, Lee JS, Kurie JM, et al. Clonal genetic alterations in the lungs of current and former smokers. J Natl Cancer Inst. 1997;89(12): 857-862.

56. Wistuba II, Lam S, Behrens C, et al. Molecular damage in the bronchial epithelium of current and former smokers. J Natl Cancer Inst. 1997; 89(18):1366-1373 
57. Weir BA, Woo MS, Getz G, et al. Characterizing the cancer genome in lung adenocarcinoma. Nature. 2007;450(7171):893-898.

58. Ding L, Getz G, Wheeler DA, et al. Somatic mutations affect key pathways in lung adenocarcinoma. Nature. 2008;455(7216):1069-1075.

59. Natrajan R, Reis-Filho JS. Next-generation sequencing applied to molecular diagnostics. Expert Rev Mol Diagn. 2011;11(4):425-444.

60. Tsou JA, Hagen JA, Carpenter CL, Laird-Offringa IA. DNA methylation analysis: a powerful new tool for lung cancer diagnosis. Oncogene. 2002;21(35):5450-5461.

61. Hoque MO, Kim MS, Ostrow KL, et al. Genome-wide promoter analysis uncovers portions of the cancer methylome. Cancer Res. 2008;68(8): 2661-2670.

62. Palmisano WA, Divine KK, Saccomanno G, et al. Predicting lung cancer by detecting aberrant promoter methylation in sputum. Cancer Res. 2000;60(21):5954-5958.

63. Schmidt B, Liebenberg V, Dietrich D, et al. SHOX2 DNA methylation is a biomarker for the diagnosis of lung cancer based on bronchial aspirates. BMC Cancer. 2010;10:600.

64. Schneider KU, Dietrich D, Fleischhacker M, et al. Correlation of SHOX2 gene amplification and DNA methylation in lung cancer tumors. BMC Cancer. 2011;11:102.

65. Xi L, Nicastri DG, El-Hefnawy T, Hughes SJ, Luketich JD, Godfrey TE. Optimal markers for real-time quantitative reverse transcription PCR detection of circulating tumor cells from melanoma, breast, colon, esophageal, head and neck, and lung cancers. Clin Chem. 2007;53(7): 1206-1215.

66. Miura N, Nakamura H, Sato R, et al. Clinical usefulness of serum telomerase reverse transcriptase (hTERT) mRNA and epidermal growth factor receptor (EGFR) mRNA as a novel tumor marker for lung cancer. Cancer Sci. 2006;97(12):1366-1373.

67. O’Donnell KA, Wentzel EA, Zeller KI, Dang CV, Mendell JT. c-Myc-regulated microRNAs modulate E2F1 expression. Nature. 2005; 435(7043):839-843.

68. Esquela-Kerscher A, Slack FJ. Oncomirs - microRNAs with a role in cancer. Nat Rev Cancer. 2006;6(4):259-269.

69. Hwang HW, Mendell JT. MicroRNAs in cell proliferation, cell death, and tumorigenesis. Br J Cancer. 2006;94(6):776-780.

70. Mitchell PS, Parkin RK, Kroh EM, et al. Circulating microRNAs as stable blood-based markers for cancer detection. Proc Natl Acad Sci USA. 2008;105(30):10513-10518.

71. Shen J, Todd NW, Zhang H, et al. Plasma microRNAs as potential biomarkers for non-small-cell lung cancer. Lab Invest. 2011;91(4): 579-587.

72. Cortez MA, Calin GA. MicroRNA identification in plasma and serum: a new tool to diagnose and monitor diseases. Expert Opin Biol Ther. 2009;9(6):703-711.

73. Shen J, Liu Z, Todd NW, et al. Diagnosis of lung cancer in individuals with solitary pulmonary nodules by plasma microRNA biomarkers BMC Cancer. 2011;11:374.
74. Boeri M, Verri C, Conte D, et al. MicroRNA signatures in tissues and plasma predict development and prognosis of computed tomography detected lung cancer. Proc Natl Acad Sci U S A. 2011;108(9):3713-3718.

75. Foss KM, Sima C, Ugolini D, Neri M, Allen KE, Weiss GJ. miR-1254 and miR-574-5p: serum-based microRNA biomarkers for early-stage non-small cell lung cancer. J Thorac Oncol. 2011;6(3):482-488.

76. Kulpa J, Wojcik E, Radkowski A, Kolodziejski L, Stasik Z. CYFRA 21-1, TPA-M, TPS, SCC-Ag and CEA in patients with squamous cell lung cancer and in chemical industry workers as a reference group. Anticancer Res. 2000;20(6D):5035-5040.

77. Kulpa J, Wojcik E, Reinfuss M, Kolodziejski L. Carcinoembryonic antigen, squamous cell carcinoma antigen, CYFRA 21-1, and neuronspecific enolase in squamous cell lung cancer patients. Clin Chem. 2002;48(11):1931-1937.

78. Bonner JA, Sloan JA, Rowland KM, et al. Significance of neuronspecific enolase levels before and during therapy for small cell lung cancer. Clin Cancer Res. 2000;6(2):597-601.

79. PatzEF Jr, Campa MJ, Gottlin EB, Kusmartseva I, Guan XR, Herndon JE. Panel of serum biomarkers for the diagnosis of lung cancer. $J$ Clin Oncol. 2007;25(35):5578-5583.

80. Cho WC, Yip TT, Yip C, et al. Identification of serum amyloid a protein as a potentially useful biomarker to monitor relapse of nasopharyngeal cancer by serum proteomic profiling. Clin Cancer Res. 2004;10(Pt 1): $43-52$.

81. Maciel CM, Junqueira M, Paschoal ME, et al. Differential proteomic serum pattern of low molecular weight proteins expressed by adenocarcinoma lung cancer patients. J Exp Ther Oncol. 2005;5(1): 31-38.

82. Huang LJ, Chen SX, Huang Y, et al. Proteomics-based identification of secreted protein dihydrodiol dehydrogenase as a novel serum markers of non-small cell lung cancer. Lung Cancer. 2006;54(1):87-94.

83. Jantus-Lewintre E, Sanmartin E, Sirera R, et al. Combined VEGF-A and VEGFR-2 concentrations in plasma: Diagnostic and prognostic implications in patients with advanced NSCLC. Lung Cancer. 2011; 74(2):326-331.

84. Han KQ, Huang G, Gao CF, et al. Identification of lung cancer patients by serum protein profiling using surface-enhanced laser desorption/ ionization time-of-flight mass spectrometry. Am J Clin Oncol. 2008; 31(2):133-139.

85. Sidransky D, Irizarry R, Califano JA, et al. Serum protein MALDI profiling to distinguish upper aerodigestive tract cancer patients from control subjects. J Natl Cancer Inst. 2003;95(22):1711-1717.

86. Tyan YC, Wu HY, Lai WW, Su WC, Liao PC. Proteomic profiling of human pleural effusion using two-dimensional nano liquid chromatography tandem mass spectrometry. J Proteome Res. 2005;4(4):1274-1286.

87. Soltermann A, Ossola R, Kilgus-Hawelski S, et al. N-glycoprotein profiling of lung adenocarcinoma pleural effusions by shotgun proteomics. Cancer. 2008;114(2):124-133.
Lung Cancer: Targets and Therapy

\section{Publish your work in this journal}

Lung Cancer: Targets and Therapy is an international, peer-reviewed, open access journal focusing on lung cancer research, identification of therapeutic targets and the optimal use of preventative and integrated treatment interventions to achieve improved outcomes, enhanced survival and quality of life for the cancer patient. Specific topics covered in the journal include:

\section{Dovepress}

Epidemiology, detection and screening; Cellular research and biomarkers; Identification of biotargets and agents with novel mechanisms of action; Optimal clinical use of existing anticancer agents, including combination therapies; Radiation and surgery; Palliative care; Patient adherence, quality of life, satisfaction; Health economic evaluations. 